\title{
A Study of Chinese Language Teaching and Learning in the Department of Chinese Studies, Nnamdi Azikiwe University, Awka, Nigeria. 尼日利亚纳姆迪.阿齐克韦大学中文系汉语教学现状调 查研究。
}

Okafor Miracle Uzochukwu ${ }^{1}$ and Miracle Uzochukwu Okafor ${ }^{2,3}$

${ }^{1}$ Affiliation not available

${ }^{2}$ Department of Chinese Studies, Chinese Studies Department, Nnamdi Azikiwe University

${ }^{3}$ Nnamdi Azikiwe University

March 23, 2021

\section{Hosted file}

A Study of Chinese Language Teaching and Learning.pdf available at https://authorea.com/ users/379349/articles/506832-a-study-of-chinese-language-teaching-and-learning-in-thedepartment-of-chinese-studies-nnamdi-azikiwe-university-awka-nigeria- $\% \mathrm{E} 5 \% \mathrm{~B} 0 \% \mathrm{BC} \% \mathrm{E} 6 \% 97 \% \mathrm{~A} 5 \%$

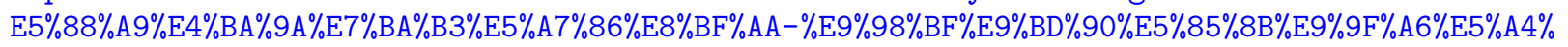

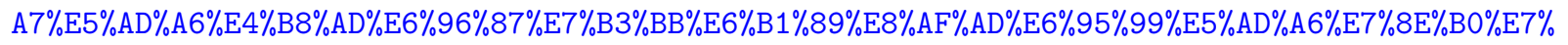
$8 \mathrm{~A} \% \mathrm{~B} 6 \% \mathrm{E} 8 \% \mathrm{~B} 0 \% 83 \% \mathrm{E} 6 \% 9 \mathrm{~F} \% \mathrm{~A} 5 \% \mathrm{E} 7 \% \mathrm{~A} 0 \% 94 \% \mathrm{E} 7 \% \mathrm{~A} 9 \% \mathrm{~B} 6$ 